\title{
Differences between left and right radial approach
}

\author{
Ivo Darko Gabrić* \\ University Hospital Center "Sestre milosrdnice", Zagreb, Croatia
}

At the beginning, transradial catheterization was developed using the left radial artery as the primary access site. However nowadays, the majority of transradial operators use right radial approach.

Results of the studies showed, that in the hands of expert operators, there were no differences in overall success rate, procedure total duration time, number of catheters used and amount of contrast used in coronary procedures used left or right radial approach. Similarly, in a series of patients undergoing $\mathrm{PCl}$ for acute myocardial infarction, no significant difference between right and left radial approaches was found in procedure success rate, procedure duration, room-to-balloon time, and safety profile.

However, the left radial artery route offers a few advantages over the right radial approach. In TALENT trial (Left Versus Right Transradial Approach for Percutaneous Coronary Procedures) 1,540 patients were randomized to either right or left radial routes. The study found that among trainees, the left radial approach was associated with a significantly shorter learning curve, reductions in cannulation and fluoroscopy times. This difference may be explained by the anatomical variations between the right and left vasculature. Right radial artery has the higher incidence of loops and the right subclavian artery is often more tortuous than the left, especially in short and elderly patients. Additionally, in the right radial approach, the catheter has to traverse two bifurcations at the right subclavian and brachiocephalic arteries, making catheter manipulation more challenging.

Sub study of TALENT trail shown that both approaches are related with similar radiation dose for operators at the body, shoulder, or thyroid level, with a possible significant lower radiation at the wrist with right radial approach.

In conclusion use of the right radial approach should be avoided in patients older than 70 years when trainee practitioners are on the learning curve.

KEYWORDS: coronarography, transradial approach, percutaneous coronary procedures.

Received: $10^{\text {th }}$ Mar 2013
*Address for correspondence: Klinički bolnički centar "Sestre milosrdnice",
Vinogradska cesta 29, HR-10000 Zagreb, Croatia.
Phone: +385-1-3787-440
E-mail: idgabric@ gmail.com

Received: $10^{\text {th }}$ Mar 2013

Vinogradska cesta 29, HR-10000 Zagreb, Croatia

E-mail: idgabric@gmail.com

\section{Literature}

1. Kiemeneij F, Laarman GJ. Percutaneous transradial artery approach for coronary stent implantation. Cathet Cardiovasc Diagn.1993;30:173-8.

2. Rao SV, Cohen MG, Kandzari DE, et al. The transradial approach to percutaneous coronary intervention: historical perspective, current concepts, and future directions. J Am Coll Cardiol. 2010;55:2187-95.

3. Sciahbasi A, Romagnoli E, Burzotta F, et al. Transradial approach (left vs right) and procedural times during percutaneous coronary procedures: TALENT study. Am Heart J. 2011;161(1):172-9.

4. Martinez CA, Cohen MG. Left or right, transradial access for all. J Invasive Carrdiol. 2010; 22(9):398-9. 